University of Wollongong

Research Online

Faculty of Social Sciences - Papers (Archive) Faculty of Arts, Social Sciences \& Humanities

2016

Gender, ethnicity and sustainable mobility: a governmentality analysis of migrant Chinese women's daily trips in Sydney

Gordon R. Waitt

University of Wollongong, gwaitt@uow.edu.au

Sophie-May Kerr

University of Wollongong, smk534@uowmail.edu.au

Natascha Klocker

University of Wollongong, natascha@uow.edu.au

Follow this and additional works at: https://ro.uow.edu.au/sspapers

Part of the Education Commons, and the Social and Behavioral Sciences Commons

Research Online is the open access institutional repository for the University of Wollongong. For further information contact the UOW Library: research-pubs@uow.edu.au 


\title{
Gender, ethnicity and sustainable mobility: a governmentality analysis of migrant Chinese women's daily trips in Sydney
}

\author{
Abstract \\ The automobile is acknowledged as an urgent environmental sustainability issue in cities where it \\ remains pivotal to everyday life and society. We explore the potential of migrants - from societies where \\ urban spaces and everyday life are not centred on the automobile - to elucidate pathways for reducing car \\ dependence. This paper explores the sustainability implications of everyday mobility decisions in Sydney, \\ Australia, through the mobility discourses of female migrants from China. Our governmentality analyses \\ suggest a preference, among female Chinese migrants, to initially walk and cycle after arriving in Sydney. \\ Many expressed a fear rather than a love of driving. For these migrant women, the decision to eventually \\ purchase and use an automobile - in the specific transport context of Sydney - was forced rather than \\ chosen. We call for others to address the reciprocal relationship between gender and ethnicity in their \\ thinking about sustainable transport.
}

\section{Keywords}

trips, daily, women's, chinese, migrant, analysis, sydney, governmentality, gender, mobility:, sustainable, ethnicity

\section{Disciplines}

Education | Social and Behavioral Sciences

\section{Publication Details}

Waitt , G., Kerr, S. \& Klocker, N. (2016). Gender, ethnicity and sustainable mobility: a governmentality analysis of migrant Chinese women's daily trips in Sydney. Applied Mobilities, 1 (1), 68-84. 


\section{Gender, ethnicity and sustainable mobility: A governmentality analysis of migrant Chinese women's daily trips in Sydney}

Gordon Waitt, Sophie-May Kerr \& Natascha Klocker

School of Geography and Sustainable Communities

University of Wollongong, New South Wales, Australia

gwaitt@uow.edu.au

\section{Abstract}

The automobile is acknowledged as an urgent environmental sustainability issue in cities where it remains pivotal to everyday life and society. We explore the potential of migrants - from societies where urban spaces and everyday life are not centred on the automobile - to elucidate pathways for reducing car dependence. This paper explores the sustainability implications of everyday mobility decisions in Sydney, Australia, through the mobility discourses of female migrants from China. Our governmentality analyses suggest a preference, among female Chinese migrants, to initially walk and cycle after arriving in Sydney. Many expressed a fear rather than a love of driving. For these migrant women, the decision to eventually purchase and use an automobile - in the specific transport context of Sydney - was forced rather than chosen. We call for others to address the reciprocal relationship between gender and ethnicity in their thinking about sustainable transport. 



\section{Introduction}

One challenge of anthropogenic climate change is a requirement for people living in cities to become less dependent on fossil fuelled private cars. We can no longer avoid Val Pulmwood's $(2007,1)$ challenge 'to imagine and work out new ways to live with the earth, to rework ourselves and our high energy, high consumption, and hyperinstrumental societies adaptively'. This is particularly the case for Australians, who have one of the largest per capita carbon footprints in the world and high levels of car dependency (Dodson and Sipe 2008). As noted by Forster (2006), Australian cities are configured by the automobile through distinctive modes of suburban dwelling and sociality. The challenge of reworking everyday transport choices in Australian cities - to be less reliant upon the car - is profound. The most recent New South Wales Transport Masterplan for Sydney signals a commitment to shift from cars to public transport, walking and cycling (New South Wales Government 2012). However, attempts to contest spaces of automobility in Sydney - by limiting parking, car mobility or closing roads - are often met by resistance (Nicholls 2013). At the heart of this paper is an investigation of what we and others have started to do - which is to better understand the intersections between gender and everyday mobility (Hanson 2010, Waitt and Harada 2012; Kent 
2015). These intersections are not only fundamental to family life but also to questions of sustainability. This paper contributes an ethnically diverse lens to discussions of sustainability and gendered mobilities by discussing the experiences of a particular group of migrants - women who were born in China, but now live in car-dependent Sydney. Women migrants provide an important and novel perspective, given evidence of the central role that private cars play in balancing work and family responsibilities, and in shaping 'mothering' identities (Dowling 2000).

The relationship between immigration and the car is well established in literature exploring the growth and configuration of Australian cities (Burnley and Fagan 1999). These debates focus on how migrants' propensity to attain home ownership, in the middle and outer suburbs of Sydney and Melbourne, have resulted in 'forced car ownership' (Currie and Senbergs 2007). The notion of 'forced car ownership', in suburbs that are poorly serviced by public transport, suggests that essentialised claims of a shared and naturalised Australian 'love affair' with the car need to be rethought. This paper seeks to build on Currie and Senbergs' (2007) challenge to rethink automobility in Australian cities as inevitable, or as a natural outcome of a 'love affair' with cars. We follow the lead of Klocker and Head (2013) who argued that strategies for developing more sustainable cities could glean important insights from the cultural 
capacities of diverse migrants. We explore the everyday transport choices of migrants from China, because earlier quantitative research showed that Chinese migrants living in metropolitan Sydney have significantly lower rates of car ownership and use than AngloAustralians, regardless of gender, age or income (Klocker et al. 2015). These findings mirrored established evidence from the USA (Tal and Handy 2010). This paper helps to explain these trends, through the everyday mobility discourses of women migrants, born in mainland China.

In China, car sales over the past decade rose meteorically, assisted by the abolition of road tolls and reduced taxes on smaller cars and fuel (Sperling and Gordon 2009).That said, car ownership rates in China remain low. In 2010, there were 58 vehicles per 1,000 persons, compared to 804 in the USA (Wang et al. 2011). In Sydney in 2011/12, there were 579 cars per 1,000 persons (Bureau of Transport Statistics 2013). Car ownership in China remains geographically concentred in the major cities of Beijing and Shanghai, and the vast majority of all trips continue to be made using public and active transport ( $\mathrm{Ng}$ et al. 2010). Significantly, He et al. $(2005,1502)$ argued that 'effective mass public transport systems will continue to remain the main choice for Chinese 
citizens in the foreseeable future'. In China, society and everyday life are not centred upon the automobile.

In what follows we first situate our argument within a growing body of literature on ethnic and gendered mobilities. We build on the work of Doughty and Murray (2014) that draws on the Foucauldian concept of governmentality in order to bring to the fore discursive and embodied imperatives of gendered subjectivities and mobilities. A governmentality framework facilitates exploration of the interplay between individual agency and the totalising power of broader institutional discourses. Next, we discuss the numerical significance of Chinese migrants within the populations of Australia and Sydney, and outline our mixed qualitative methodology. The total study sample incorporated 18 first and second generation Chinese migrants (male and female) living in Sydney, Australia. In this paper, our account draws on mobility narratives of five women of a similar cohort generation who were born in China and the affiliated territory of Taiwan to provide insights into how gender, generational difference, ethnicity and environmental sustainability are manifest through everyday mobility practices. Our interviewees' mobility patterns support Hanson's (2010) assertion that women's mobility is more environmentally sustainable than men's travel: they make less use of the car, travel short distances in the car and use more public 
transport. Yet, at the same time, their narratives raise important questions about social equity in mobility. Do these migrant women who drive less understand their mobility as constrained or free, imposed or chosen? To answer these questions we examine how meaning and identity were expressed within our interviewees' mobility narratives through an analysis of embodied discourses of risk, modernity and gendered freedom and/or constraint. To conclude, we argue that decision makers in their design of sustainable transport policy need to be attentive to the relationships between different modes of mobilities and the everyday performances of parenting and working lives.

\section{Ethnic diversity and gender in mobilities research}

Ethnicity and gender have an important bearing on transport behaviour. Existing research on this topic has been largely quantitative, examining ethnic and gendered differences in travel activity patterns as recorded in large-scale travel surveys, particularly in the USA. In general, lower rates of private car use and ownership are indicated for ethnic minorities and migrants, compared to ethnic majority and native-born populations. Socio-economic disadvantage is a key variable to account for ethnic differences in mobility (Bohon et al. 2008, Golub et al. 2013; Grengs 2010, Lovejoy and Handy 2008, Valenzuela et al. 2005). However, a number of studies undertaken in the USA (Douma 2004; Modarres 2013; 
Tal and Handy 2010) and one in Australia (Klocker et al. 2015), indicate that below-average rates of car ownership and use amongst ethnic minorities and/or migrants remain statistically significant after controlling for income differences (by using established statistical techniques such as regression analyses). Thus, while income is an important factor, the distinct transport behaviours of diverse ethnic groups cannot be explained solely by socio-economic differences. These studies conclude that cultural factors are likely also at play. The qualitative study reported on in this paper provided an opportunity to investigate such assertions.

Similarly, large travel activity surveys demonstrate the lower spatial mobility of women compared to men. Gendered analyses of mobility indicate that women are more likely to work from home, travel shorter distances to work and are less likely to engage in work-related overnight travel (Cristaldi 2005; Polk 2004, Crane 2007). Furthermore, in many nations, women conduct a statistically greater proportion of their travel on foot, and complete more trips by public transport (and fewer by car) than do men (Rosenbloom 2006; Srinivasan 2008; Vance and lovanna 2007). Such findings hold cross-nationally, regardless of age, education, income or marital status. These findings indicate that geographical, social and cultural contexts that sustain gender and ethnic differences in 
everyday transport behaviour are worthy of further, qualitative, exploration.

Qualitative studies provide important insights into how everyday transport choices both shape, and are shaped by, gender and ethnicity. They detail the reciprocal relationships between mobilities, identities, emotion and power. Gendered experiences of mobility have attracted considerable qualitative research attention (Clarsen 2014, Cresswell and Uteng 2008, Hanson 2010). One strand of qualitative research employs performative ontologies to explore how gendered driving subjects are produced and reproduced through language. For instance, Scharff (1991) described the discrimination that women drivers have faced given the historical weight of ideas aligning cars with masculinity. Racialized mobilities have also garnered some research attention. For instance, Ahmed (1997) drew attention to the over-regulation of black driving bodies in Australia, through racial profiling. An important but small body of research, informed by performative ontologies, has brought racialized and gendered mobilities into combined focus. Gilroy (2001) provided a critique of the racialized marketing of automobility to African American men to illustrate the intersections between power, gender, race and car mobility. Gilroy $(2001,94)$ coined the term 'compensatory prestige' to argue that prestige car advertising tapped into discourses of freedom 
and independence that run counter to broader patterns of marginalisation and discrimination that affect African American men. Jain (2002), meanwhile, investigated the marketing of Sports Utility Vehicles (SUVs) to 'white' nuclear families in the USA. Selling SUVs relied upon reproducing dominant white masculine understandings of 'nature' as an untouched wilderness, out there, just waiting to be explored, alongside middle-class understandings of feminine respectability tied to domestic responsibilities including child-care and shopping. In turn, Dowling's (2000) ethnographic research illustrated how driving SUVs facilitates the performance of gendered, classed and racialized ideas of the 'good' professional mother in Melbourne, Australia. More recently, Hannam (2016) provided insights into the seemingly contradictory gendered freedoms and constraints facing Pakistani women in Saudi Arabia, where women are not allowed to drive on public roads. Such work illustrates how the physical car itself is inscribed with meanings that reproduce and reflect intersecting societal ideas about gender, class and ethnicity.

A second strand of qualitative mobilities research, that compliments the first, draws on affective ontologies associated with non-dualist relational philosophies including Thrift's non-representational theory (Sheller 2004) and Deleuze and Guattari's concept of assemblage (see Waitt et al. 
2015). This strand foregrounds the embodied dimensions of what happens inside the car during prosaic trips. It pays attention to the bodily feelings generated by assemblages of people, things and spaces-on-the move. This work underscores the relationships between the emotions engendered by car mobilities and how the subject positions of car drivers become racialized, gendered and classed. For example, Sheller (2004) explored how the emotions generated by sheer movement - in the car, together with children - may actively affirm ideologies of 'good' mothering amongst middle class white women. Likewise, Jensen et al.'s (2015) ethnographic study of daily Danish family mobility extended this approach, through an exploration of how 'good' parenting is embedded in the affordances of different transport modes. Waitt et al (2015) pointed to the importance of considering the subject positions sustained through the quasi private movement-space of the car when women are driving alone as well as together with children and partners. Some women experience driving alone as an opportunity to escape gendered domestic constraints, and to imagine different futures, through the embodied socio-material relations of automobility.

To explore the relationship between gender, ethnicity and sustainable transport, this paper builds on a third emergent strand of research that engages with Foucault's $(1982,221)$ concept of governmentality - 
specifically, the 'conduct of conduct' (see Doughty and Murray 2014).

We favour this strand of research because the concept of

governmentality acknowledges individual agency while remaining alert to connections within the totalising power of institutions and the state, which legitimise particular knowledge as 'true'. On the one hand, to enquire into everyday mobility requires thinking about how wider-societal institutions and organisations permeate individual transport decisionmaking processes. On the other hand, individual everyday travel and mobility choices offer possibilities for self-reflection, self-knowledge and self-examination. Hence, the concept of governmentality provides a conceptual framework to explore the relationship between the broader totalising power of institutional discourses and individual agency exerted through embodied accounts of mobile lives. Our interpretation was guided by two questions: How do the embodied everyday transport narratives of women migrants from China convey understandings of themselves, and of their relationships with particular modes of transport? How have these understandings shifted, over time, in the distinct transport context of Sydney?

\section{Methodology}

People born in China constituted the second largest migrant group to Australia in 2011/12, exceeded only by migrants from India (Department 
of Immigration and Citizenship (DlaC) 2013). In recent years, migration from China has increased due to successive Commonwealth Government skilled migration policies. Chinese-born people make up four per cent of Sydney's population (Australian Bureau of Statistics (ABS) 2014). At the time of the most recent Census, China was the third most common country of birth for residents of Greater Sydney (following Australia and England, ABS 2011).

To secure insights into mobility patterns of Chinese migrants living in Sydney a mixed-method qualitative research approach was adopted, incorporating semi-structured interviews and sketch maps of 'everyday journeys', alongside optional travel diaries and photographs or video recordings of everyday trips. These methods reflect a narrative approach. Narrative approaches have much to offer mobility scholars (Murray 2009). For a start, they enable participants to tell stories about their everyday travel experiences that attend to biographies, context and idiosyncrasy. As Doughty and Murray $(2014,9)$ argued, 'participants' biographies as well as collective memories are key elements in forming local mobility discourses.' Second, storytelling was particularly appropriate for this cross-cultural project because mobility narratives provide insights into how participants organise their experiences of movement into meaningful episodes that help make sense of 
themselves, relationships with family members and an automobile society. Third, storytelling facilitates understandings of the reciprocal relationships between (im)mobilities, subjectivities, society and place. Telling stories about mobile practices and experiences of different modes of transport may both reproduce and challenge dominant norms regarding the relationships between bodies, time, spaces, subjectivities and societies. Consequently, research participants' stories draw attention to the politics of narrative and how individuals move around Sydney. Here, we are particularly interested in the intersections between gender and ethnicity in female Chinese migrants' embodied discourses of mobility. Our motive in exploring these discourses was to better understand the factors that support or constrain the less car-intensive (and thus, more environmentally sustainable) transport behaviours of Chinese households in Sydney, that were identified in Klocker et al.'s (2015) quantitative study.

Eighteen participants were recruited through targeted, opportunistic and snowball sampling in 2014 from metropolitan Sydney, on the east coast of Australia. All participants spoke English fluently and had lived in Sydney for at least three years. Twelve participants were women, and six participants were men. Thirteen participants were born in mainland China and affiliated territories, two in Australia, two in Malaysia and one 
in New Zealand. All participants self-identified as being of Chinese ancestry. For the purpose of exploring the relationship of female Chinese migrants to automobility we focus on those who are aged between 20 and 45 years of age from mainland China and affiliated territory of Taiwan. Five participants comprised this younger-generation cohort. Of these five participants, four were married, and two were mothers with children under five years of age. One participant lived with her mother. All were in paid employment and were comfortably middleclass. These women had not owned cars in China, and only one had a driver's licence prior to migration. However, since arriving in Australia, all of them had obtained a licence and owned a car at the time of interview. As discussed throughout this paper, car ownership was considered an essential - but not enjoyable - aspect of managing everyday life and gendered family responsibilities in Sydney.

Participants were interviewed twice about their daily mobilities. The first interview was themed to provide a transport life narrative in order to explore how they narrated their mobilities across their geographical pasts and presents. The second interview focussed on the everyday mobility practices documented in participants' travel diaries and drawings. These materials became a prompt for the co-production of knowledge with participants exploring particular events (weather, 
missing pubic transport, waiting, parking, traffic congestion); practices (shopping, childcare, elder care, reading, social media use, singing); or choice of routes or of transport mode. For the purposes of this paper, the primary data source is the interview data. Our interpretation of the interviews relied upon a combination of discourse and narrative analysis as discussed by Waitt (2005) and Wiles et al. (2005), respectively. Three everyday mobility discourses emerged from coding and analysis of interview data: discourses of mobile risk; discourses of modernity; and discourses of gendered freedom and/or constraint. These discourses illustrate what Fredendal-Pedersen (2009) termed 'the structural stories' that naturalise car ownership. On the one hand they offer an important counterpoint to the structural story of 'Australians' love affair with the car'. On the other hand they highlight the immense pressures of structural stories around the car experienced by migrants as mothers and employees, to develop less environmentally sustainable transport behaviours post-migration.

\section{Embodied discourses of mobile risk}

Previous work on mobility highlights discourses of mobile riskiness in automobilised urban spaces (Murray 2009; McLaren and Parusel 2015). This work draws of Foucault's notion of 'dangerousness' to explain why particular modes of transport, drivers of particular gender or ethnicity, or 
indeed brand of car, are constituted as more or less safe - even when not borne out by statistical evidence (Urry 2007; Sheller and Urry 2003; Packer 2008). Automoblised spaces are constituted as dangerous because they are neither bounded nor fixed. Discourses of how to be mobile in urban spaces to accommodate automobility were narrated by participants as central to their transition into Australian life. These discourses were framed by parental concerns over the dangers of walking and cycling in Sydney - modes of transport which had dominated the interviewees' pre-migration lives in China. Chen (23 years-of-age, born China, aged 13 years old at time of migration, married, coupled household) explained why cycling and walking are not 'practical' in an automobile society, like Sydney:

When I came to Australia I am so used to walking and maybe bicycle to get everywhere so that would be my main choice to walk everywhere. But in time you will learn that it's not practical to walk everywhere in Australia so you move on to public transport and a car.

Chen went on to explain how, as a teenager growing up in Australia, discourses that naturalised car mobility were reinforced by the levels of bodily exertion demanded by Sydney's topography, and parental concerns over child safety:

When I came here it's much more different like we had a car and I've never had a car in my whole life and I was maybe like 13 and 
"Oh I have a car". And it's very exciting. And then you realise that you can't walk in Australia [be]cause there are a lot of concerns with the road and the people. Like, when I came here my parents told me "you're not allowed to walk by yourself or even with your brother"...They actually told me, "you have to be careful. There are a lot of bad people on the road. You don't speak English". So they made us mainly to catch a bus or get in a car. And then you realise the roads here it's much more harder to walk; it's like up-hill and then down-hill and everywhere it's really far.

More driving, and less walking was initially understood as 'exciting'. Yet, Chen came to experience less walking as disempowering. Within dominant western cultures of parenting, driving is normalised based on the portrayal of quasi-private car spaces as relatively 'safe', when compared to the dangers of independently walking or cycling in and through the spaces of automobile societies (Bostock 2001). Through the imposition of a parental escort, Chen and her brother lost their independent mobility as teenagers living in highly automobilised Sydney:

When I came here you don't have that walk to school with friends anymore. Everyone lives so far away. And you know, being able to actually visit your friends it was much nicer to just be able to go to somewhere together [in China]... whereas, here it was not as easy to do. I can't think that I walked one hour to visit my friends ever, after I've been in Australia. It is much different...So I would generally just stay at home and do my stuff. My brother is always very naughty. He will actually go out in the middle of the night to visit his friends [laughs]. And, he will just go out through the back door. And, I asked him: "How did you get to your friend's place?", "Oh I just walked!" Yeah literally he walked from Blakehurst to Hurstville. That was an hour walk each way at two o'clock in the morning! 
Chen's lower mobility as teenager arriving in Australia was understood as constraining. Her brother walking alone became understood as an act of defiance.

Similarly, Lee (23 years-of-age, born China, aged 13 years old at time of migration, single, lives with mother) discussed how changes to individual transport behaviour - post-migration - are reflective of how the automobile constructs not only the dangers and safety of social life, but also how parents negotiate spatially contingent ideas of risk by immobilising their children:

When I was in China I used to ride a bike everyday but now I couldn't [be]cause there is no bike lanes in Australia and it would be really dangerous to ride a bike on the road. And, so, yeah, mum would never let me ride a bike even though I used to ride bike everyday in China ... But now mum won't let me [be]cause there is no bike lane in Australia so it would be dangerous.

For these migrants, after arriving in Sydney, cycling and walking became embedded in embodied discourses of risk, deviancy and physical effort. Discussions with Chen and Lee illustrated how cycling and walking were identified as risky mobilities for children in Australia that did not readily connect with being a 'good' son or daughter - despite being common practice in China. In automobilised Sydney, the only ways for parents to avoid risk were for their children to catch public transport, accept a 
parental escort or remain relatively immobile. For migrating families, learning to skilfully manage traffic risk - by adopting less sustainable transport behaviours - was positioned as being essential to transition to the parenting norms of middle-class Australian family life. As explored later in this paper, the automobility system, in turn, informed the research participants' own parenting decisions, in the present day.

\section{Embodied discourse of modernity}

Well established in the mobilities literature is the pivotal role of the automobile in sustaining the concept of modernity (Cresswell 2006; Urry 2007). Driving a car is naturalised as part of modern life. Automobility is embedded in discourses of flexibility, speed, convenience and freedom. Car ownership is often unquestioned, even in cities with public transport networks, because the car is positioned not only as a 'right', but as essential for social mobility and economic success. In this section we explore how discourses of modernity shape mobility patterns of migrant women and vice versa.

For our participants, embodied discourses of modernity played a key role in shaping mobility practices, particularly in sustaining ethnic generational differences and through the perceived importance of driving in facilitating women's access to paid employment. Participants 
delineated car mobility as 'modern'. The ability to drive set them apart from older and (in their words) 'more traditional' Chinese migrants living in Sydney. A pervasive discourse - amongst these younger Chinese women, living in Sydney - positioned walking and public transport as markers of generational change:

Old [Chinese] people still have a lot of things in the blood they [are] still remembering, like I see a lot of Chinese walking from Penshurst to Hurstville that takes half an hour which they do. But the young people not much. But old people sometimes carry the bags I see and think: 'Oh so heavy'. But they still do a lot of shopping and come back...Still, I believe old people use more public transport, bus, trains, than [the] young, yeah I believe... Because [the] young come here and learn [Australian norms] so quick (Xia [early 40s, born China, aged 30 years old at time of migration, married, nuclear family household])

Likewise, Chen described older Chinese women, walking through streets encumbered with heavy shopping bags or pushing shopping trolleys, as a key indicator of ethnic generational difference:

I know all the ladies that come to this centre [Hurstville shopping centre] actually live in my neighbourhood and every single day I see them walking [laughs] with their little pram. And I will be hopping in the car while they are walking somewhere. And I say, "Where you going?" And they go, "Just having a walk"... am talking about people maybe 60 [years] plus. And their mindset is even much more than me. Like they are more into walking, happy, healthy and walk their grandchildren...They have more of the Chinese tradition and when you are 50 or 60 you don't change your way of living. If you go to Hurstville... if you go there at like 7:00 or 8:00 [a.m.]...you don't see Aussie people going shopping at 7:00 in the morning, you see all these [Chinese] grandmothers 
with their little trolleys. And that's what they do. And they do their shopping every single day and it's very early in the morning.

Walking to the shops, pushing a trolley was narrated as old-fashioned. It was narrated, by the interviewees, as an essentialised Chinese and gendered practice, embedded in a post-migration context. Through place (in this case, Hurstville in Sydney), gendered, ethnic and generational differences in mobility are given a spatial referent, and become a social fact. By narrating the practice of 'Chinese grandmothers' (walking to the shops early in the morning with 'little trolleys'), our interviewees positioned themselves as members of a 'modern', younger Australian-Chinese generation of car-drivers.

For our interviewees, driving was also associated with the lifestyle of a 'modern' working woman, living in Sydney. Some participants spoke about initially travelling to work by foot, public transport or bicycle. But within an automobile society, it was difficult to regard themselves as productive, professional employees when riding a bicycle or catching public transport to work. Car mobility was imposed rather than chosen by participants. For example, Xia narrated the 'truth' about herself as a good employee through the purchase of a car:

Ah yes, when I came to Australia the first few years I didn't have a car and in China I never have a car... I used to ride bicycle in China, that's my main transport. Now not much, because it is not 
very right here. [I] can't ride on the road because it is so dangerous, ride on the pedestrian [footpath] is very harmful for the people who are walking so it's not easy here, in China it's much easier...When I come to Australia I buy a bike I think bike is cool and then later on I realise this is not working over here... when I come to Australia totally different system so I have to choose system that [works] here rather than in China, so I changed the way of thinking as well...have to do the same as Australia[ns] ....Yeah so the first few years is hard because everybody else in the company [where I work] drives cars apart from me. So, everyday the [other] people still can keep working. And, I am running out to catch the bus. So that's very difficult. Actually I didn't want to learn to drive until...I had to. I have no choice because I live in that place, because it's too far from industrial area, far from everywhere. So difficult. So that's the reason I learn to drive.

Xia's Sydney mobility initially involved no driving. At first, cycling felt 'cool'. However, using a bicycle was experienced as disempowering in an automobile society. Xia was forced to learn to drive, so that she could work longer hours alongside her colleagues. Likewise, Lee explained how car mobility was imposed by the constraints of public transport rather than chosen. For Lee, the ability to drive opened up job opportunities:

I think [I] only really started using a car as a transportation probably five years ago, yeah five or six years ago... I have more opportunity of finding a job and then, like that job really taught me a lot, I grew a lot from that job...It's just really convenient [to drive a car] and the opportunity of having more opportunity and more choices to go to places. And, uh, [it] saves a lot of time.

Lee experienced car mobility as empowering, because it opened new opportunities for her. By contrast, Qi (mid 30s, born China, aged 26 at 
time of migration, married, coupled household) described being compelled to purchase a car to travel to work through the constraints of property ownership and public transport:

I had a driver's license when I was in China but I didn't own a car... [In Sydney] I always end up [with] the jobs not located in the centre of the city, instead always in suburb all around, so [l] end up drive around. And, in the past before I bought the house I was renting, so during that time I always moved to somewhere close to work...l always find a job first and then move close to the location. But now [I have] bought this property I can't move anymore [laughs].

After having become accustomed to driving, Qi developed an embodied disposition that reinforced car mobility as essential for economic productivity:

I just don't like squeeze myself into the train which take too much energy and then by the time I get to the office I don't feel I have too much energy to work for the whole day.

Qi's comments illustrate how embodied dispositions of the car, developed post-migration, can come to play a significant role in the counter-performativity of public transport. Qi initially started driving in Sydney out of necessity. But, over time, the car became a necessary tool for coping with working life in Sydney (see also Waitt et al. 2015). The car was justified in participants' narratives to overcome the constraints of active and public transport, maximise their productive use of time, secure employment, and speedy connectivity to bring home and 
work closer together. Taken together, these narratives illustrate the sustainability paradox of car mobility: provision of greater equity of access to all in a spatially fragmented automobile society entails greater use of renewable resources and higher greenhouse gases and other emissions.

\section{Embodied discourses of gendered freedom and /or constraint} In western countries, driving is positioned as the touchstone of empowerment, freedom and independence for the modern neo-liberal citizen (Adey 2009; Paterson 2007; Cresswell 2010). Automobility is conceived as a right. Australia is no exception. Waitt and Harada (2012) documented that for residents living in an affluent middle class Sydney suburb, car driving represented individual liberty. Yet, none of the participants in the present study narrated learning to drive in terms of autonomy, or as a red-letter day for independent movement. Some noted that having a licence and car made them an exception, within their female Chinese friendship circles in Sydney:

I do know most...Chinese, especially girls, they don't prefer to drive, they even don't know how to drive. I was surprised and some of these people they live in Australia for many many years and they don't know how to drive. The girls, and I have a quite close girl-friend....she's been in Australia for probably 20 years. And she always is get[ting] work in the city, so her major transportation is by train...She can play her mobile and answer her 
emails and [be] sending messages to each person, during the time she is in the train (Qi).

The inability to drive was not narrated as a gendered constraint on these women's lives. In this case, contrary to Massey (1993), lack of equal access to mobility was not narrated as evidence of women's subjugation. Indeed, there is a freedom identified in the above quotation - in travelling to work by train and using a mobile phone. Echoing the work of Hannam (2016) on Pakistani women not driving in Saudi Arabia, this narrative points to the mobility ambivalences that are narrated by some women migrants from China, who live in Sydney.

Notably absent in the mobility narratives of our interviewees were stories exemplifying learning to drive as a pivotal milestone in terms of individual autonomy of movement (see Doughty and Murray 2014). Instead, alongside securing employability, passing driving tests and purchasing first cars were often narrated in terms of legitimised mobile cultures of mothering. For these women, driving was a means to an end. They learned to drive in Sydney because they felt they had little choice to fulfil particular gendered mothering roles. In Chen's account, learning to drive was disempowering - because she was forced to do so by her Anglo-Australian partner: 
When I lived by myself [in Sydney] so maybe for 5 years I didn't have a car.... never had a need for cars, I always just got by walking to places and catching public transport. And, my husband really forced me to drive so when you are being forced to do something you never really like it, no matter if it is convenient or not you just don't like it... He thinks it's essential to drive in Australia because he said if we have a family and you're going to be a stay at home mother, you will be in charge of driving the kids to school...it was almost one of the conditions before we got married. I fought many times with him, I would be crying, literally crying in the car, so I just refuse[d] to drive and he would drop the bomb and say, 'If you don't know how to drive I don't really know if I can marry you'.....and he is really serious about it, so that's why I keep on trying and so you just see me crying driving and he was very adamant I had to drive.

This quotation illustrates how hetropatriarchal gender relationships of mothering shape car mobility. As discussed by Dowling (2000), car mobility in Australia is essential in constructing mothering identities based on gendered white middle-class parents' aspirations for their children. Chen had no agency in learning to drive. Chen's ability to drive was fundamental to sustaining her Anglo-Australian partner's view of her identity as a wife and mother, and conventional gender ideologies and practices.

Over time, our participants came to view the car as an essential tool within practices of care for children and family. Chen and Linda made a point of distinguishing the car as a tool, from the car as a status symbol. 
The little blue car, which my husband is very proud of [laughs]...my friends drive Porsche and BMW and all that. But for me because I never had a car it's not that important. But, I want to have a car that's more functional (Chen).

Ah it's [the car] just a tool [laughs], yeah it's okay I don't really care too much about car because I still go to work by train, by public transport so the car like we only bought because we['ve] got a young kid and sometimes it's hard to travel around with him by the public transport, so yeah that's why (Linda [early 30s, grew up in Taiwan, aged 19 at time of migration, married, nuclear household]).

This finding echoes Hjorthol's (2008) observation that Norwegian women who comply with dominant cultures of mothering (predicated on risk aversion) are more likely than men to constitute cars as a parenting tool, rather than a status symbol. The car is a 'coping strategy' that enables these women to live up to the gendered expectations and responsibilities of modern family life (Murray 2008, 47; McLaren and Parusel 2015). For the participants in this study, Sydney's public transport system was deemed too hard, fragmented and unwieldy for meeting parenting responsibilities. For example, Xia told of how the car enables her to travel to multiple places to fulfil her responsibilities as a mother, while also working full-time. Her schedule would not be feasible by public transport:

Ah if I have to bring him [her child] to school that's very important because the school [is] not close to the station, but close to the bus stop, but the bus take[s] a very long time to his pre-school, so if I drive it take[s] 5-10minutes, if I take the bus it takes about 45 
minutes!...So I have a routine, Tuesday here, Monday swimming, go to story time, go to [the] library ...um playgroup, mummies' group, I used to go to the mummies' group but he is a little bit older now, very busy. Very difficult yeah...If I use the public transport that's too much because I have to get up so early and he can't get up so early and I can get up but he can't, so I [would] always [be] rushing and always [be] late to the school, if I don't have a car.

Xia's comments illustrate Triver's $(1988,86)$ argument that a hetropatriarchal ideology 'assigns child-caring responsibility to women'. Furthermore, her narrative provides a good example of Murray's (2008, 56) point that ' $[\mathrm{m}] \mathrm{otherhood}$ practices are not only increasingly mobile but potentially hypermobile'. As convincingly argued by Murray (2008), within a car-driven society, the automobile mother is coerced into 'intense flexibility' (Urry 2000, 191). An important point is how Xia's spatial movement is constrained by gendered childcare responsibilities and middle-class expectations of 'good' mothering', discussed by Dowling (2000). Bauman (1988) and Freudendal-Pederson (2009) referred to the unintended constraints of gaining more freedom afforded by the car as 'unfreedom'. For Xia, the car ameliorates constraints on time and mobility imposed by mothering practices. Xia explained how the stresses of reaching multiple destinations, which are characteristic of the hyper-mobile life of the working Sydney mother, are eased by the car: 
[The car] it's convenient, wherever you want to go and whenever it's just quick and fast yeah and safe...yeah it's easier. But yeah, time is so precious for mum, so if we go and get somewhere it is much easier then public transport because I have to walk 15-20 minutes to the station, I have to wait maybe another 15-20 minutes...to get someplace and then you have to walk again, so yeah definitely car.

Despite Xia's initial fear of driving, the car liberates her from the temporal and spatial constraints of public transport in Sydney. Xia's comments tapped into the pervasive discourse according to which the ease of car mobility and productive use of time are represented as convenient. Yet, her spatial patterns of everyday mobility are constrained by gendered practices of care. Xia has adopted the culture of mobile parenting which reflects dominant middle-class cultural norms in Australia of 'good' mothering, and which is bound up in combining work with childcare outside the home (Barker 2003, Miller 2005).

Linda also pointed to the importance of the car in being a 'good parent', optimising the productive use of family time at weekends and maintaining a social life. The social is shaped by car mobility, and the enjoyment of not being encumbered by prams and bags:

I think we [Linda and her husband] just gave up on social life because it just took too much time on travelling with the pram, especially if there is track work [on the railway line]. You have to change stations and stations. And just too time consuming. And sometimes [we] just say: 'Oh it's too much [effort] to go'... [That] 
means if we don't have a car we probably just give up and won't go to place[s]... Because he [the baby] gets impatient quiet easily, so it's easier to just put him in the car and drive (Linda).

As Valentine $(1997,49)$ argued: 'Although taking prime responsibility for children is a major constraint on women's lives which can undermine their own sense of self, motherhood can also give women a sense of meaning and identity.' Car mobility, therefore, can both constrain and liberate women's lives in the context of spatially contingent cultures of mothering.

As shown throughout this discussion, the justifications for car ownership expressed by the Chinese migrant women interviewed in this study were dominated by discourses of modernity, safety, 'good parenting' and coping with the demands of everyday life in a car dependent city. These women felt compelled - and in some instances, coerced - to learn to drive (in order to be good employees and mothers), but regularly associated driving with reluctance and fear. While car driving was narrated as safer than walking or cycling - in the automobilised context of Sydney - our interviewees were simultaneously fearful of driving, and anxious about their own driving skills:

[It's] just not pleasant...I can't tell you the amount of times I'm stuck in the traffic lights and just can't move. So, I think memories just aren't as fond when I drive. It's a hassle to take the car...Uh, I generally don't like driving at all, like every time I drive I think I am 
going to crash [laughs]. Like every time I get in the car I'm like, 'Oh my god I have to drive!'(Chen).

Uh, I believe that initially I [was] scared because I didn't know how to drive, when I come to Australia, but okay now. I have [to] drive for a while, it's okay (Xia).

I kind of [am] scared to drive in Sydney because there's speed so fast. It's quite serious...So that's probably another reason why I [prefer to] take public transport ... Once you get lost [driving] it's quite scary (Linda).

Our interviewees' embodied discourses of driving conveyed 'fear' and 'dislike' rather than 'enjoyment' or 'love' of speedy connectivity (Murray 2009). But, faced with the automobilised spaces of everyday life in Sydney, these women became regular (if reluctant) car drivers over time to meet the demands placed on them as 'modern' working women, and as mothers.

The narratives of coercion and feelings of fear expressed by these women challenge dominant narratives that position driving as 'enjoying' the freedom of speedy connectivity, and as the epitome of independence (Doughty and Murray 2014). In these interviews, car mobility was acknowledged as a necessary part of life in Sydney. But these narratives also emphasised driving as a hassle, potential accidents, traffic congestion and concerns about the dangers of fast moving traffic and getting lost. These participants' concerns mirror Beckmann's $(2001,604)$ 
point that the car's promise of freedom can actually turn against itself. For Chinese migrant women living in Sydney, this was certainly the case. The purported freedom of the car became a constraint - because they had little choice but to become car drivers.

\section{Conclusion}

Climate change and broader agendas of sustainable cities demand strategies for reducing car dependence in policy agendas. Reducing the carbon emissions from cars will have to include the possibilities of more people catching public transport, walking and cycling. We take our lead from Doughty and Murray (2014), to provide a governmentality analysis of the embodied mobility discourses of migrant women from China.

These women came to Sydney from a society where everyday life is not grounded in the routines and rhythms of automobiles. Our findings point to how gendered, ethnic and classed subjectivities are spatially made and remade. Such insights are essential to sustainability policies that seek to replace car journeys with trips on foot, bicycles or public transport.

Alive to how the conduct of gender, class and ethnicity shape and are shaped by mobility, the interviewees in this study provide two important clues for sustainable transport planning in Sydney. First, these women's 
narratives illustrate the propensity that some migrants bring with them to use automobilised space differently - by using public transport, walking and cycling more, and driving less. This propensity is always mediated by how spatial mobility affirms or undermines social status by confirming understandings of professional, gender, generational and ethnic identities. Our work suggests that sustainable transport policy must remain alert to the performative dimensions of mobility. This requires paying attention to how discourses shape 'risk' and identities. The study suggests that there are social risks of having different ideas about how to move about the automobilised city. In political terms, driving needs to be recognised as important for maintaining identities, including those of the 'modern' working woman and 'good' mother.

Second, the embodied mobility discourses presented in this paper highlight that sustainable transport initiatives could benefit from better understanding how these migrant women contested automobility in their everyday practices. Our interviewees' transport narratives did not tap into dominant discourses that naturalises particular modes of transport. In this case, they did not tap into the structural story of Australians' love affair with the car. This is important because this structural story is often used to explain or justify car mobility as a 'right', and thus works against political change. Yet, as shown in this paper, this structural story is a 
highly exclusionary one: it prioritises the norms and preferences of some Australians (e.g. Anglo-European, Australian-born) over others (e.g. certain groups of migrants and ethnic minorities). When our interviewees learnt to drive a car, it was imposed by constraints of an automobilised society. While they eschewed one structural story of automobility (that of a love affair with the car), they became entangled in others - that of the 'good' mother (Dowling 2000; Freudendal-Pedersen 2009); and that of the 'modern' worker. Over time (post-migration) they became convinced that to juggle the demands of parenting and work in Sydney, it is impossible to be dependent on public transport, cycling or walking. For the women in this study, car ownership was closely associated with connections between mobility, gendered parenting roles and professional working lives. Alongside the convenience and freedom of car mobility, participants' narratives were alert to and often emphasised the constraints or 'unfreedoms' of automobility including opting out of cycling, walking and public transport and in one case complying with the cultural norms surrounding domestic roles of an Anglo-Australian husband. This study identified that planning for sustainable transport futures needs to recognise how dominant discourses and experienced need inform everyday mobility choices. Future sustainable transport research in automobile societies could productively draw on Foucault's notion of governmentality to explore how migrants negotiate dominant 
discourses surrounding different types of mobility. Answering this question will provide helpful insights into what type of person one aims to become through different modes of mobility. These insights, in turn, provide a novel perspective on the conundrum of a sustainability that is environmentally and socially just.

\section{Acknowledgements}

First we would like to thank the participants who generously gave their time. We are also grateful for the constructive guidance on earlier drafts from referees. Funding for this research was provided by the Australian Research Council, Discovery Grant (DP140101165).

\section{References}

Adey, P. 2009. Mobility. London and New York: Routledge.

Ahmed, S.1997. 'It's a sun-tan, isn't it?' Auto-biography as an Identificatory Practice." In Black British Feminism: A reader, edited by M. H. Dafia, 153-167. London: Routledge.

Australian Bureau of Statistics (ABS) 2014. Australian Social Trends, cat. no. 4102.0, Canberra: Commonwealth of Australia. Accessed 23 January 2016, http://www.abs.gov.au/social trends

Australian Bureau of Statistics (ABS), 2011. General Social Survey Results, Australia, 2010. cat. no. 4159.0. Canberra: Commonwealth of Australia. Accessed 23 January 2016, http://www.abs.gov.au/ausstats/abs@nfs/mf/4159.0

Bauman, Z. 1988. Freedom. Berkeley: Open University Press.

Barker, J. 2003. "Passengers or Political Actors? Children's Participation in Transport Policy and the Micro Political Geographies of the Family." Space and Polity 7 (2):135-51.

Beckmann, J. 2001. "Automobility - a Social Problem and Theoretical Concept." Environment and Planning D: Society and Space 19 (5): 593607. 
Bohon, S., Stamps, K. and J. Atiles. 2008. "Transport and migrant adjustment in Georgia." Population Research and Policy Review 27 (3): 273-291.

Bostock, L. 2001. "Pathways to Disadvantage? Walking as a Mode of Transport Among low Income Mothers." Health and Social Care in the Community 9 (1):11-18.

Bureau of Transport Statistics, 2013. 201/12 Household Travel Survey, Summary Report 2013 Release. Sydney: NSW Government.

Burnley, I. and R. Fagan.1999. Immigration and Australian Cities. Leichardt, New South Wales: Federation Press.

Clarsen, G. 2014. Feminism and Gender. In The Routledge Handbook of Mobilities, edited by P. Adey, D. Bissell, K. Hannam and M. Sheller, London: Routledge.

Cresswell, T. and T. P. Uteng. 2008. "Gendered Mobilities: Towards an Holistic Understanding." In Gendered Mobilities edited by T. P. Uteng and T. Cresswell, 47-64. Aldershot: Ashgate.

Cresswell, T. 2010. "Towards Politics of Mobility." Environment and Planning D: Society and Space 28: 17-31.

Cresswell, T., 2006. "The Right to Mobility: The Production of Mobility in The Courtroom.' Antipode 38 (4), p.735 - 754.

Cristaldi, F. 2005. "Commuting and Gender in Italy: A methodological issue." The Professional Geographer 57 (2): 268-84.

Currie, G. and Z. Senbergs. 2007. "Exploring Forced Car Ownership in Metropolitan Melbourne." Proceedings of 30th Australasian Transportation Research Forum. 25-27 September Melbourne, Crane 2007).Accessed 23 January 2016, http://atrf.info/papers/2007/index.aspx

Department of Immigration and Citizenship (DlaC) 2013. Annual Report 2012/13. Canberra: Commonwealth of Australia.

Dodson, J. and N. Sipe. 2008. Unsettling Suburbia: The New Landscape of Oil and Mortgage Vulnerability in Australian Cities. Gold Coast: Griffith University. 
Doughty, K. and L. Murray. 2014. "Discourses of Mobility: Institutions, Everyday Lives and Embodiment." Mobilities, DOI:

10.1080/17450101.2014.941257

Douma, F. 2004, "Using ITS to Better Serve Diverse Populations." Minnesota: Minnesota Department of Transportation Research Services Section.

Dowling, R, 2000. "Cultures of Mothering and car use in Suburban Sydney: a Preliminary investigation.” Geoforum 32 (3): 345-353.

Forster, C. 2006. "The Challenge of Australian Cities and Urban Planning in the New Millennium." Geographical Research 44: 173-182.

Foucault, M. 1982. "The Subject and Power." In: Michel Foucault: Beyond Structuralism and Hermeneutics edited by $\mathrm{H}$. L Dreyfus and P. Rabinow, 208-226. Chicago: University of Chicago Press.

Freudendal-Pederson, M. (2009) Mobility in Daily Life: Between Freedom and Unfreedom. Farnham: Ashgate

Gilroy, P. 2001. "Driving While Black." In: Car Cultures edited by D. Miller, 81-104, Oxford: Berg.

Golub, A., Marcantonio, R. and T. Sanchez. 2013. "Race, Space and Struggles for Mobility: Transportation Impacts on African Americans in Oakland and the East Bay." Urban Geography, 34 (5): 699-728.

Grengs, J. 2010. "Job Accessibility and the Modal Mismatch in Detroit." Journal of Transport Geography 18 (1): 42-54.

Hannam, K. 2016. "Gendered Automobilities: Female Pakistani Migrants Driving in Saudi Arabia." In

Hanson, S. 2010. "Gender and Mobility: New Approaches for Informing Sustainability." Gender, Place \& Culture: A Journal of Feminist Geography 17 (1): 5-23.

He, K., Huo, H., Zhang, Q., He, D., An, F., Wang, M. and M, Walsh. 2005. "Oil Consumption and CO2 Emissions in China's Road Transport: Current Status, Future Trends, and Policy Implications." Energy Policy, 33(12): 1499-1507. 
Hjorthol, R. 2008. "Daily Mobility of Men and Women - a Barometer of Gender Equality." In: Gendered Mobilities, edited by T. P. Uteny and T. Cresswell, 193-212. London: Ashgate.

Jain, S. L. 2002. "Urban Errands: The Means of Mobility." Journal of Consumer Culture 2 (3):385-404.

Jensen, O. B., Sheller, M., and S. Wind. 2015. "Together and Apart. Affective Ambiences and Negotiation in Families' Everyday Life and Mobility." Mobilities, 10 (3): 363-382.

Kent, J. L. 2015. Still Feeling the Car - The Role of Comfort in Sustaining Private Car Use. Mobilities 10 (5) 726-747.

Klocker, N. and L. Head. 2013. "Diversifying Ethnicity in Australia's Population and Environment Debates." Australian Geographer 44 (1): 41-62.

Klocker, N., Toole, S. Tindale, A. and S-M. Kerr. 2015. "Ethnically Diverse Transport Behaviours: an Australian Perspective." Geographical Research, 53 (4): 393-405.

Lovejoy, K. and S. Handy. 2008. "A Case for Measuring Individuals' Access to Private-Vehicle Travel as a Matter of Degrees: Lessons From Focus Groups with Mexican Immigrants in California." Transportation 35 (5): 601-612.

Massey, D. 1993. "Power-Geometry and a Progressive Sense of Place. In: Mapping the Futures: Local Cultures, Global Change, edited by J. Bird, B. Curtis, T. Putnam, G. Robertson, and L. Tickner, 60-69. New York: Routledge.

McLaren, A. T. and S. Parusel. 2015." 'Watching Like a Hawk': Gendered Parenting in Automobilised Urban Spaces." Gender, Place \& Culture, 22 (10): 1426-1444.

Miller, T. 2005. Making Sense of Motherhood. Cambridge: Cambridge University Press.

Modarres, A. 2013. "Commuting and Energy Consumption: Toward an Equitable Transportation Policy." Journal of Transport Geography, 33: 240-249. 
Murray, L. 2009. "Making the Journey to School: The Gendered and Generational Aspects of Risk in Constructing Everyday Mobility.' Health, Risk \& Society 11 (5) 471-486.

Murray, L. 2008. "Motherhood, Risk and Everyday Mobilities." In: Gendered Mobilities, edited by T. P. Uteng and T. Cresswell, 47-64. Aldershot: Ashgate.

New South Wales Government 2012. New South Wales Long Term Transport Masterplan. Sydney: NSW Government.

Ng, W., Schipper, L. and Y. Chen. 2010, "China Motorization Trends." The Journal of Transport and Land Use 3 (3): 5-25.

Nicholls, S. 2013. "Not in my Front Yard Say Light Rail Opponents." Domain, Sydney Morning Herald, April 18, Accessed 23 January 2016, http://www.domain.com.au/news/not-in-my-front-yard-say-light-railopponents-20130417-2hz5h/

Packer, J. 2008. Mobility without Mayhem, Safety, Cars and Citizenship. Durham: Duke University Press.

Paterson, M. 2007. Automobile Politics: Ecology and Cultural Political Economy. Cambridge: Cambridge University Press.

Polk, M. 2003. "Are Women Potentially More Accommodating Than Men to a Sustainable Transport System?" Transportation Research Part D 8: 75-95.

Pulmwood, V. 2007. "A Review of Deborah Bird Rose's Reports From a Wild Country: Ethics of Decolonisation." Australian Humanities Review 42: 1-4.

Rosenbloom, S. 2006. “Understanding Women's and Men's Travel Patterns: The Research Challenge." In: Research on Women's Issues in Transportation: Volume 1 Conference Overview and Plenary Papers, Conference Proceedings 35, 7-28. Washington, DC: National Research Council.

Scharff, V.1991. Taking the Wheel: Women and the Coming of the Motor Age. New York: Free Press.

Sheller, M. 2004. "Automotive Emotions; Felling the Car." Theory, Culture \& Society 21 (4/5): 221-242. 
Sheller, M., and J. Urry. 2003. "Mobile Transformations of 'Public' and 'Private' Life." Theory, Culture and Society 20: 107-125.

Sperling D. and D. Gordon 2009. Two Billions Cars: Driving Towards Sustainability. New York: Oxford University Press.

Srinivasan, S. 2008. "A Spatial Exploration of the Accessibility of LowIncome Women: Chengdu, China and Chennai, India." In: Gendered Mobilities, edited by T. Cresswell and T.P. Uteng, 143-58. Burlington, VT: Ashgate.

Tal, G and S. Handy. 2010. "Travel behaviour of immigrants: an analysis of the 2001 National Household Transportation Survey." Transport Policy 17 (2): 85-93.

Triver, J. 1988. "Women with Young Children: Constraints on Activities in the Urban Environment." In Women in Cities, edited by J. Little, L. Peake and P. Richardson, 84-97. Basingstoke: Macmillan Education.

Urry, J. 2007. Mobilities. Cambridge: Polity.

Valentine, G. 1997. "My son's a bit Dizzy. My Wife's a bit Soft: Gender, Children and Cultures of Parenting." Gender, Place \& Culture 4: 37-62.

Valenzuela, A. Schweitzer, L. and A. Robles. 2005. "Camionetas: Informal Travel Among Immigrants." Transportation Research Part A 39 (10): 895-911.

Vance, C. and R. lovanna 2007. "Gender and the Automobile: Analysis of Nonwork Service Trips." Transportation Research Record 2013: 5461.

Wang Y., Teter, J. and D. Sperling. 2011. "China's Soaring Vehicle Population: Even Greater Than Forecasted?" Energy Policy 39 (6): 3296-3306.

Waitt, G. and T. Harada 2012. "Driving, cities and changing climates." Urban Studies 47 (15): 3307-3325

Waitt, G, Harada, T. and M. Duffy 2015. "Let's have some music': Sound, gender and car mobility." Mobilities, DOI:

10.1080/17450101.2015.1076628 
Waitt, G. R. 2005. "Doing Discourse Analysis." In: Qualitative Research Methods in Human Geography edited by I. Hay,163-191. London: Oxford University Press.

Wiles, J.L. Rosenberg, M. W. and R. A Kearns 2005. "Narrative Analysis as a Strategy for Understanding Interview Talk in Geographic Research." Area 37 (1): 89-99. 